\title{
La influencia de la intelectual peruana en el desarrollo del papel de la mujer de inicios del siglo $\mathrm{XX}$
}

The Peruvian intellectual influence in the development of the woman paper on the beginnings of the twenty century

\author{
Janet Díaz Manunta \\ Universidad Peruana de Ciencias Aplicadas, Lima, Perú \\ Contacto: jdiaz@upc.edu.pe \\ http://orcid.org/0000-0003-3739-0586
}

\begin{abstract}
Resumen
El propósito de este artículo es revisar la literatura periodística de mujeres a inicios del siglo XX. Esta es un instrumento de análisis del pensamiento colectivo que la intelectual mujer poseía y que determinó - tanto de manera directa como indirecta - los futuros cambios socioculturales.

Durante las dos primeras décadas del siglo XX, las intelectuales trabajaron un tema de fondo: el acceso de la mujer a la educación y a un trabajo digno. Esta temática fue planteada desde distintos puntos de vista, los cuales generaron debates y rivalidades entre las mismas enunciantes. Este estudio gira alrededor del artículo de Mercedes Cabello de Carbonera, "Los exámenes".
\end{abstract}

Palabras clave: Intelectual mujer; Desarrollo cultural; Derecho a la educación; Mercedes Cabello de Carbonera

\begin{abstract}
The intention of this article is to revise women's journalistic literature at the beginning of the twentieth century. This in an instrument of analysis of the collective thinking that the intellectual woman owned, and, that caused - directly or indirectly - the future sociocultural changes.

During the two first decades of the twentieth century, the intellectual women worked on a crux subject: woman's access to education and to a decent job. This central theme was considered since several points of view, which created discussions and arguments between the same writers. This study revolves around of Mercedes Cabello de Carbonera's article, "The exams".
\end{abstract}

Keywords: Intellectual woman; Cultural development; Right to education; Mercedes Cabello de Carbonera

Recibido: 20.11 .18

Aceptado: 15.02 .20 


\section{Introducción}

Las escritoras mujeres de los inicios del siglo XX no fueron ajenas a contienda alguna, ya sea esta la lucha obrera, el reconocimiento de los derechos de la mujer a la educación y a un trabajo digno, el trato al indio como sujeto autosuficiente, etc. El medio para expresar estas ideas, disquisiciones y hasta conflictos internos entre las mismas pensadoras fue, en su gran mayoría, la prensa.

A través de este medio, el sujeto enunciante va a traspasar sus inquietudes y posturas frente a la realidad que lo circunda. Cabe acotar que, para estos años, aún no había un lugar determinado (respetado y canonizado) para la literatura escrita por mujeres. La intelectual fue construyendo paulatinamente su tribuna de expresión a través de dicha prensa (revistas, panfletos, semanarios, diarios, etc.). Asimismo, estas intelectuales continuaron con su labor literaria a través de poemarios, cuentos, obras teatrales y discursos (verbalizados y, luego, publicados).

Uno de los principales temas que rodeó a dichas escritoras (sean ellas provenientes de la ciudad, de la provincia o extranjeras asentadas en Lima) fue el papel de la mujer en el desarrollo del país no solo como sujeto individual, sino como sujeto colectivo. Rol que demandaba el otorgamiento de derechos básicos a las mismas, pues, sin educación y un trabajo digno, tal función social era irrealizable.

Escritoras como Juana Manuela Gorriti (1818-1892), Teresa González de Fanning (1836-1918), Mercedes Cabello de Carbonera (1842-1909), Carolina Freyre de Jaimes (1844-1916), Lastenia Larriva de Llona (1848-1924), Clorinda Matto de Turner (1852-1909), Elvira García y García Bert (1862-1951), Zoila Aurora Cáceres Moreno (1877-1958) y María Jesús Alvarado Rivera (18781971), entre las principales, compartían el sentimiento de evidenciar la necesidad de la mujer por educarse (véanse sus obras cardinales en la bibliografía). De esta forma, la propuesta en común de dichas intelectuales daba énfasis en que el sujeto mujer debía tener acceso al campo laboral con un salario respetable y en condiciones justas en cuanto a género ${ }^{1}$.

Sin embargo, una parte de la sociedad, coetánea a ellas, consideró que esta propuesta distorsionaba los roles del hombre y de la mujer en el hogar, ya que, de acuerdo con los cánones sociales, dichas funciones eran inalterables. Dentro de este último grupo se incluye a las mismas intelectuales mujeres, quienes, frente a 
la ola de necesidades y cambios, tuvieron que procesar la importancia del nuevo papel que la mujer debía asumir y la situación que se le presentaba para hacerlo. Tal aceptación, negación o parcial entendimiento demoró poco para algunas o fue un período largo para otras.

Las iniciativas, las propuestas y los debates se acentuaron gracias a la inacción del ente estatal, pues - como institución que debía defender los derechos de sus ciudadanos, en este caso, del ciudadano mujer - no acogía esta problemática como propia y dejaba que se siga dilatando. El sujeto enunciante mujer contaba con un sistema político de corte patriarcal que no comprendía la necesidad del desarrollo del sujeto mujer en pro del progreso de la misma comunidad. Aunado a ello, la institución religiosa fue juez y parte en este dilema.

Los prejuicios sobre la capacidad enunciativa de la escritora mujer fueron otro factor para su minimización, tanto de varones como de las mismas mujeres, quienes habían hecho de la división de roles una parte inalterable de su inconsciente colectivo. Se perdió, entonces, la objetividad y, como consecuencia principal, se desvalorizó la labor escritural de la mujer; con ello, el pensamiento de esta sociedad en etapa de tránsito entró en varios conflictos.

Un ejemplo de lo previamente acotado se encuentra en el libro Carácter de la literatura del Perú independiente (De la Riva-Agüero, 2008 [1905], p. 173). En esta obra, el autor realiza comentarios despectivos sobre la producción de la escritora Juana Manuela Gorriti:

Dispenséme el lector mi falta de galantería, perdone la airada sombra de la ilustre dama argentina que tánto y tan de veras amó al Perú, mi ruda franqueza: en los frutos del ingenio de la señora Gorriti (lo mismo que en los de las señoras que concurrían á su tertulia) á primera vista se distingue á la bas $b l e u^{2}$. Sería seguramente, puesto que los que la conocieron lo afirman, mujer discreta, de trato agradable y distinguido; pero como escritora me parece detestable. Son sus obras de las más tediosas, afectadas y tontas que produjo la escuela romántica.

Sin duda alguna, la posibilidad de las intelectuales de expresarse a través de lo no-ficcional y lo ficcional acentuó la desconfiguración de los roles masculino/femenino de la época: "constituyó una subversión, por cuanto empezaron a apropiarse de la tribuna pública" (Ortiz, 2018, p. 118). 


\section{Propuestas, réplicas y pensamientos ${ }^{3}$}

\section{1 "Las obreras del pensamiento", de Clorinda Matto de Turner}

El 14 de diciembre de 1895, Matto de Turner dio un discurso en el Ateneo de Buenos Aires cuyo título fue "Las obreras del pensamiento en la América del Sur". En él, la autora resalta el papel de la mujer en el "rol de la ilustración" de su tiempo:

Mujer, e interesada en todo lo que atañe a mi sexo, he de consagrarle el contingente de mis esfuerzos que, seguramente, en el rol de la ilustración que la mujer ha alcanzado en los postrimeros días del siglo llamado admirable, será un grano de incienso depositado en el fuego sacro que impulsa el carro del progreso, y, aunque éste no producirá la columna de luz que se levanta en los Estados Unidos del Norte, pretendiendo abarcar la América, él dará, siquiera, la blanquecina espiral que perfuma el santuario.

[...] la mujer, silenciosa y resignada, cruzó barreras de siglos repitiendo apenas, con miedoso sigilo, las mágicas palabras: libertad, derecho. [...] Así como del choque de la piedra pedernal y el acero brota la chispa, al golpe de dos martillazos, uno en el Gólgota, otro en la Bastilla, centelló la luz para la causa de la mujer, quedando en la ceniza del oscurantismo las cadenas que sujetaban su cuerpo y embrutecían su alma. (Matto, 2006, p. 169)

El discurso de la autora se fundamenta en los ámbitos espiritual y sociopolítico, y en los tránsitos de ambos en el devenir del desarrollo humano. Dichos interludios históricos han permitido que la mujer ilustrada se vaya incorporando como sujeto influyente de su propio progreso. El Gólgota —lugar donde Cristo fue crucificado- y la Bastilla, escenario simbólico del inicio de la Revolución francesa, son las dos bisagras que Matto utiliza. A través de la primera, el ser humano pasa del pecado a la gracia; con la segunda, el ciudadano termina con la opresión monárquica y obtiene el reconocimiento de sus derechos.

Cabe acotar que Matto siempre propugnó el respeto por lo católico a nivel espiritual; sin embargo, en cuanto a la labor de sus representantes, mantuvo una crítica constante. Esto último respondía a diversos factores, tales como el papel grandilocuente que se les daba a los religiosos dentro de la formación cultural peruana o a su injerencia en las cuestiones políticas del país. Lo anterior se puede evidenciar claramente en su libro Aves sin nido [1889] (Matto, 2006), en el cual, sin desmerecer lo que significa la religión, la autora desaprueba a quienes la encarnaban. 
Asimismo, Matto recalca que el "postergar la ilustración de la mujer es retardar la ilustración de la humanidad". Ello se justifica con "la proclamación del principio sociológico: el trabajo con libertad, dignifica; el trabajo con esclavitud, humilla" (Matto, 2006, p. 170). Por eso, la necesidad de las "obreras del pensamiento", pues las intelectuales conformaban la voz, que respondía al eco de una multitud, y que, al mismo tiempo, emitía mensajes de concientización. Las obreras del pensamiento serían todas aquellas mujeres que "no sólo dan hijos a la patria, sino, iprosperidad y gloria!” (Matto, 2006, p. 171).

\section{2 "Los exámenes", de Mercedes Cabello de Carbonera}

El 11 de enero de 1898, en el diario El Comercio, Mercedes Cabello de Carbonera publicó un artículo que llevó como título: “Los exámenes” y como indicación “(En el colegio de la Señorita Elvira García y García)”4. La temática de ese trabajo giró en torno a la educación de la mujer y al cómo esta se debería impartir para evitar la formación equívoca de las féminas. Para lograr tal propósito, Cabello planteó restringir el derecho, casi exclusivo, de las congregaciones religiosas de educar a las niñas y a las jóvenes. Esto debido a que dichas instituciones no estaban impartiendo una educación que pudiese ayudar a las futuras mujeres a asumir un rol funcional y real en la vida. En otras palabras, Cabello exigía una enseñanza laica, la cual debía ser dada por los mismos padres de familia y por un profesorado capacitado, tal como lo realizaba Elvira García y García o como lo había llevado a cabo Teresa González de Fanning.

Cabello veía a la institución clerical como un ente de corrupción, perteneciente a las grandes esferas, y a las monjas como un grupo de personas incapaces de brindar una educación digna para la mujer. Ello en la medida que la instrucción que se impartía no forjaba mujeres profesionales, libres pensadoras o capacitadas para un trabajo. Sus planteamientos fueron demasiado innovadores para la época y no armonizaron con el tipo de lector conservador y patriarcal que los recibió:

Yo diría que la Fisiología es la ciencia por excelencia de la mujer.

Ella le enseña a la madre, cuando apenas siente los primeros latidos del hijo que lleva en las entrañas, la influencia que las impresiones de la madre ejerce sobre el hijo; ella le enseña, cómo el músculo débil del niño puede cambiarse por medio del ejercicio, en músculo fornido, cual si fuera de acero fundido; ella, a la madre previsora, le señala la 
época de la pubertad del niño; época peligrosísima en que la ignorancia y el descuido de las madres conducen a los hijos a la idiotez o a la insanidad. [...]

¡Una monja enseñando Fisiología...! ¡Qué ilusión!... ¡Qué sarcasmo para la moral social...! (Cabello, 2017, pp. 348-349)

Aunado a lo ya mencionado, la autora invitó a que el curso de religión no se impartiera en los colegios, ya que este ocultaba la verdad de la historia del clero a las educandas:

Siguió luego la clase de Historia Antigua [y] de la Edad Media, y las niñas con la soltura y la convicción de un hombre que sabe lo que dice, hablaban refiriéndose a la época del feudalismo y de la corrupción del clero, de ese clero sensual, ignorante, corrompido del que todavía nos quedan abundantes muestras que, como los epidópteros carcomen nuestro edificio social, [...] y mientras las bellas y simpáticas niñas hablaban así, yo pensaba y reflexionaba, cómo se expedirían los hijos de Loyola, y las madrecitas de gorra alona, para hablar a las niñas de esas fechorías que sus fundadores muy amados padres cometieron...? (Cabello, 2017, p. 349)

La razón fundamental de toda esta crítica se centraba en el rol de la mujer en la sociedad, pues con el continuismo de un sistema educativo religioso imperfecto y con la no-inserción de los padres de familia en la educación de sus hijas no se forjarían ciudadanas reales. "La religión no debe enseñarse en los colegios; dado que el hijo debe ser obediente y sumiso a los mandatos paternales" (Cabello, 2017, pp. 348-349).

La crítica de Cabello se sustenta en el valor medular que tiene la labor de la mujer tanto como hija, madre, jefa de familia y ciudadana. Esta idea es reafirmada a lo largo de todo su texto. Uno de los puntos polémicos de "Los exámenes" fue la afirmación de Cabello de que el presidente de la República le había encomendado la misión de velar por la educación de las niñas en el Perú, aseveración sin fundamento alguno.

\section{3 "Réplica ineludible", de Lastenia Larriva de Llona}

Las reacciones a favor y en contra del texto de Cabello no se hicieron esperar. Una de las primeras, y de oposición radical, fue la de Lastenia Larriva de Llona. Ella, en un artículo titulado "Réplica ineludible" (18 de enero de 1898), publicado por el diario El Comercio en su edición vespertina, responde punto por punto a su colega. 
Para lograr tal propósito, Larriva emplea argumentos que, aunque no cumplen totalmente con una función apelativa frente a lo expuesto por Cabello de Carbonera, revelan el pensamiento en pugna de la época; este se ubicaba entre una cultura patriarcal con base religiosa y roles de género definidos, y un nuevo orden que permitiera que la mujer posea mayores oportunidades y derechos. Los postulados de Larriva de Llona retratan el sentir de un grupo de ciudadanos y el suyo propio. Para el caso particular de la autora, se evidencia su perspectiva personal de madre y mujer. Las opiniones vertidas en su texto serán de gran influencia para sus lectores y lectoras, y de gran utilidad para los adversarios de Cabello. Por otro lado, para aquellas intelectuales que coincidían con Cabello, Larriva no quebró la lucha, sino que la alimentó:

[...] lo raro, lo absurdo, lo temerario, no está tanto en los espíritus pusilánimes que tienen miedo de afrontar la opinión de los que no piensan como ellos; lo raro, lo absurdo, lo temerario, está en la sociedad, en la colectividad de personas en que predomina esa falta de religión absoluta, esa perversión completa de las ideas, ese atroz falseamiento de las nociones de Moral que dan por resultado el que al hombre piadoso se le mire como á un ser enteramente exótico, cómo a un desequilibrado, digno solo de lástima ó desdén.......

La mujer, el ser débil por naturaleza, suele dar, sin embargo, al hombre grandes y frecuentes ejemplos de valor físico y moral. En los tiempos de los emperadores romanos, eran ellas las que aceptaban el martirio con mayor entereza y serenidad; y en los actuales tiempos, somos también nosotras, las que, —salvo rarísimas excepciones- no renegamos jamás de nuestras santas creencias, sino que alardeamos de ellas á la faz del mundo; y aún nos atrevemos á salir en su defensa siempre que las miramos combatidas ú ofendidas.

Ofendidos juzgo yo ahora mis sentimientos de católica, mi dignidad de mujer, mi amor de madre y mi altivez de peruana con el artículo de la señora Mercedes Cabello de Carbonera, titulado Los exámenes. (Larriva, 1898, p. 3)

Claramente, se percibe el desconcierto de Larriva de Llona frente a lo escrito por Cabello, específicamente, a lo referido a la "Moral". Sin embargo, para combatir dicha molestia, la autora recurre a falacias subjetivas como las que se han seleccionado en la siguiente cita:

Sé que no tengo el talento ni la ilustración de la señora de Carbonera; y sin embargo me creo más competente que ella para fallar en la cuestión de la educación de los niños. La razón es muy obvia: - La señora de 
Carbonera ha tenido una gran desgracia de no tener hijos. Yo tengo la inmensa dicha de ser madre.

Tengo tres hijas educadas en el Convento de los Sagrados Corazones; hablo, por tanto, con conocimiento de causa. Pues bien, declaro con toda la veracidad de que soy capaz, puesta la mano sobre el corazón; sobre mi corazón lleno del más inmenso amor maternal; que esas religiosas cumplen la santa misión de educar a las niñas que se confían a sus cuidados, con celo, con una abnegación y una inteligencia que casi exceden a las facultades humanas. (Larriva, 1898, p. 3)

Lo consignado anteriormente apela a la autoridad de la experiencia propia de ser madre y de haber educado a las hijas en un colegio religioso. Cabe destacar el respeto y la admiración con los cuales la autora describe a las monjas, a quienes les otorga cualidades propias de la providencia. Mas, hasta este punto, sus postulados son insustentables para entablar una defensa o réplica válida.

Por otro lado, en cuanto a las cualidades que desarrolla una joven en un colegio religioso, Larriva destaca las siguientes:

[...] es verdad que las reverendas Madres creen que vale más para una niña - y aun para una mujer - saber orar por los delincuentes, que saber maldecir a los inquisidores; y ser dirigidas por un confesor más bien que por sus pasiones incipientes; pero es por eso mismo, porque atienden al espíritu antes que a la materia, que las niñas educadas por las monjas son las hijas más respetuosas y las esposas más sumisas. (Larriva, 1898, p. 3)

"Hijas más respetuosas" y "esposas más sumisas" son los dos valores fruto de la educación dada por las monjas. Para consolidar tales atributos, se agrega el hecho de que al sujeto mujer se le debe tener en constante cuidado para que no sea protagonista de "pasiones incipientes". Este estereotipo femenino atraviesa siglos de historia. Su origen se encarna en la figura de Eva, personaje bíblico del libro del Génesis, a quien se le minimiza por haber caído ante la tentación de la serpiente y se le culpa de haber convencido a Adán de hacerlo también. La debilidad es, por ende, femenina, así como la tentación, pues el hacer de la serpiente se le traspasa a Eva al haber generado que Adán haya comido la manzana prohibida.

Lo anterior ha formado parte del inconsciente colectivo del ser humano. La cultura patriarcal, antes de explicar que ese hecho relatado en la Biblia es solo una metáfora, como muchas otras vertidas, tanto en el Antiguo como en el 
Nuevo Testamento, afianzó la diferencia de caracteres entre el hombre y la mujer. Las cualidades negativas — la traición, la lujuria, etc. — le fueron asignadas a la mujer como la debilidad. Por el contrario, al hombre se le atribuyó la madurez, la objetividad, el raciocinio, entre otras cosas. En pleno final del siglo XIX y a puertas del inicio de un nuevo siglo, una de las intelectuales más reconocidas del país, una obrera del pensamiento latinoamericano, manifiesta que esta situación diferencial se mantiene porque es así como debe ser.

Otro punto que es abordado por Larriva de Llona se centra en los colegios no religiosos, su profesorado y su dirección. A diferencia de Cabello, Larriva les da supremacía a los colegios regidos por las congregaciones religiosas. Asimismo, realza la dedicación y el trabajo de las educadoras de estos, las monjas, quienes - al consagrarse exclusivamente a su labor de maestras y guías en los colegios - brindan todo su tiempo a las estudiantes. Todo lo contrario sucede con el profesorado laico, en su total mayoría mujeres, quienes, por su condición de género, no podrían centrar toda su atención en el cuidado de las alumnas:

La Directora de un colegio particular lo es, no sólo porque a ello la impulsa su vocación, sino también, y sobre todo, para obtener por este medio - ciertamente muy honroso- lo necesario para su subsistencia. Antes que atender a los niños, tiene que atender a sus propias necesidades de todo género. Tiene afectos, que precisamente ocupan en su corazón un lugar preferente al que reserva para las criaturas confiadas a su cuidado; tiene intereses mundanos que cuidar necesariamente; pues ningún voto la ha obligado a separarse de la sociedad. Si es soltera, puede tener un amor correspondido - pues con ello en puridad de verdad, no comete ningún pecado- pero de todas estas circunstancias ha de resentirse, como es natural, el cumplimiento de sus deberes para con sus alumnas. Además, es ella sola, o a lo sumo cuenta con una o dos auxiliares. ¿Cómo podrá velar sobre ciento cincuenta o doscientas niñas, de diversas edades, de diverso carácter, de diversas costumbres, con toda la asiduidad que se requiere en tal caso? Una congregación de monjas dedicada a la enseñanza consta de treinta, cuarenta o sesenta religiosas, todas consagradas exclusivamente al servicio de Dios y a la educación de esos pequeños seres, de los que no se separan un instante ni de día ni de noche, y cuyo sueño velan, reemplazándose por turnos. (Larriva, 1898, p. 3)

"Réplica ineludible" termina siendo la expresión de un Perú conservador, de un grupo etario que creció con ideales religiosos y marcos sociales patriarcales. 
Este texto devela la conciencia de un gran colectivo de peruanos enraizados en dichos lineamientos. Asimismo, en el mencionado documento, se remarca la clara diferenciación entre un ciudadano común y alguien entregado a la vida sacerdotal o religiosa. Separación propia de la mitificación desmesurada hacia los representantes de la Iglesia, con la cual se les otorgaba un respeto obligatorio. El ciudadano común, que no poseía dicha vocación, no podía dedicarse exclusivamente a ser un educador, solo el sujeto religioso. Para el caso de la educadora mujer, su dedicación no solo era parcial, sino interesada y hasta negativa (mundana).

Larriva de Llona complementa toda su crítica con una apreciación a la sumisión de la mujer más que interesante:

Creemos, por el contrario, que lo que cumple a la persona a quien se confie tan delicado y honroso encargo, es buscar eficazmente los medios de perfeccionar y reforzar, sobre todo, la educación moral y religiosa de la mujer, para que ésta, adquiriendo la consciencia de su propio valer, de la misión trascendental y elevadísima a que está llamada a desempeñar en la sociedad humana del decisivo influjo que debe ejercer en la trabajosa lucha de la existencia — comprenda que, si por ley divina debe estar sometida al hombre como hija y como esposa, esa misma ley le prohíbe obedecer al padre o al marido antes que a Dios y que sea, conforme á las profundas palabras que la Iglesia pronuncia en el solemne instante del matrimonio "la compañera y no la sierva del hombre". (Larriva, 1898, p. 3)

A partir de esta toma de posición y de sus posteriores trabajos periodísticos y ensayísticos, Larriva fue catalogada como una conservadora inquebrantable y como una de las intelectuales que se benefició del gobierno a cambio de difundir su posición en contra de los cambios propuestos por sus coetáneas.

\subsection{González de Fanning: lo pedagógico, lo moral y lo sociológico}

La polémica entre Cabello y Larriva produjo la reacción de muchos intelectuales, de la sociedad en general, así como de las instituciones gubernamentales y religiosas. Una de las voces que fue trabajando los puntos vertidos en tal altercado sobre la educación y el profesorado laico, la dinámica de los cursos para las mujeres y la necesidad de una educación para todas sin excepción alguna - fue Teresa González de Fanning. Ella publicó en el diario El Comercio, a través de una serie de artículos, su análisis del problema, el cual se puede resumir en su apoyo a lo 
expuesto por Cabello de Carbonera. Sus observaciones fueron mesuradas, con ejemplos veraces y sin ningún tipo de ofensa al clero. Dichos textos se compilaron en el libro Educación femenina: colección de artículos pedagógicos, morales y sociológicos, publicado en 1898 como folleto, pues tuvo como finalidad que sea repartido gratuitamente al público peruano. Esta labor estuvo a cargo de los intelectuales que le dieron su apoyo a Cabello y que encontraron en González una voz de autoridad5. La segunda edición, que cuenta con las correcciones de la autora y agregados sobre el tema, se publicó en 1905 (debido al agotamiento de la edición anterior y a pedido del público lector); con esta se trabaja a continuación.

Las indirectas hacia Larriva de Llona recorren los artículos de González, quien evidenció su apoyo a las proposiciones de Cabello, aunque sus enunciados fueron presentados con mayor prudencia que los de su predecesora:

Esas páginas tienden á establecer que los padres son y deben ser los jefes, no aparentes sino efectivos de la familia; y que, inquiriendo los deberes que la Naturaleza la Religión y un bien comprendido amor á sus hijos les imponen, están obligados á cumplirlos con decisión y firmeza; desligándose de influencias perniciosas y del espíritu de imitación y de pueril vanidad que no pocas veces los induce á abdicar sus más sagrados derechos y á entregar incondicionalmente, so pretexto de religión, la dirección moral de sus hijas y su iniciación en la vida social, á cargo de maestras incompetentes ó sumisas á intereses sectarios que están en desacuerdo con los de la sociedad y la familia. (González, 1905, p. VIII)

A lo largo de su texto, la autora interpela al lector constantemente sobre qué es lo que requiere una joven para ser educada. Una primera respuesta es presentada a través de una analogía: "Eso equivale á pretender que un ciego enseñe la pintura ó un sordo el canto" (González, 1905, p. 3). Tal apreciación prioriza que no se puede instruir a alguien sobre algo de lo cual uno no ha sido parte y que no ha vivido realmente.

Otro punto a destacar se refiere al tiempo en que las hijas eran dejadas en los colegios de monjas; muchas veces, este se extendía hasta que las alumnas cumplían los 18 años. Se colige, entonces, que ellas no vivían en la casa paterna y, por ende, que no aprendían de sus padres la realidad de la vida o que no compartían con sus madres las tareas propias de su sexo. Los colegios de congregaciones no existieron siempre, pero sí las madres de familia. Por ello, para González, el derecho de crianza no estaba siendo otorgado a quien debía ostentarlo. 
Por otro lado, la crítica plantea que si una mujer puede educar a sus hijas en casa, qué problema habría si esta misma enseña a las hijas de otras madres, específicamente, como profesora:

En cuanto á la instrucción religiosa que se da en los colegios laicos, bastará decir que, aparte del acendrado fervor que distingue por lo general á la mujer peruana, las Directoras de colegio están obligadas á seguir el Plan de Estudios que prescribe la enseñanza de los cursos de Catecismo, Religión, Historia Santa, Vida de Jesús é Historia Eclesiástica. Además, las internas son llevadas á misa en los días de precepto; y raro será el colegio en que no se las acostumbre á rezar el rosario, y alguna otra devoción. De suerte que en la parte moral y religiosa, en la que pudiéramos llamar la parte psicológica de la educación, no reconocemos superioridad en los institutos monacales sobre los laicos. (González, 1905, p. 6)

Entonces, ¿por qué desvalorizar el trabajo de los colegios no pertenecientes a las congregaciones y el de las profesoras laicas?

La maestra peruana consume sus modestos ahorros en preparar lucidos exámenes que pongan de manifiesto ante los padres de familia y ante el público, los progresos que, mediante sus esfuerzos han hecho sus discípulas durante el año; esfuerzos que suelen ser premiados con el vacío durante las actuaciones, y un lleno completo el día de la fiesta de distribución de premios. Las monjas no se dan esa pena: ellas mismas, á puerta cerrada, examinan á las niñas y les adjudican los premios. A la distribución de éstos, sí, suelen ser invitados los padres de familia que miden los progresos de sus hijos en razón de los premios obtenidos. (González, 1905, pp. 13-14)

Luego de la cita anterior, la problemática queda aún más clara: los colegios religiosos tenían autonomía en la enseñanza; en otras palabras, carecían del deber de informar sobre el cómo impartían la educación, por cuántas horas y sus métodos de evaluación. Los padres no eran partícipes ni copartícipes de lo antes mencionado, debido a la indiferencia social y estatal ante el problema.

Los dos puntos clave que aborda el planteamiento de González son: el tipo de crianza que se daba a las mujeres en los colegios y la preparación de sus profesoras. Todo lo anterior ya lo había dicho Cabello de Carbonera en "Los exámenes", pero no de la misma manera. La réplica de Larriva, para algunos críticos, frenó una propuesta en común de varias intelectuales que pedían cambios en el 
sistema educativo y oportunidades laborales para la mujer, en este último caso, como maestras de escuela. ¿Qué es lo que realmente detuvo el completo avance del cambio?, ¿qué interrumpió esta prédica? Ya no fue la Guerra con Chile ni los problemas económicos, sino que fueron los mismos intelectuales, tanto hombres como mujeres, que dejaron de lado esta realidad, al no tomar en cuenta la importancia de una educación funcional para el género femenino. Una frase, de antes y ahora, que ayuda a vislumbrar dicha indolencia, como bien destaca González, es: “-_Se educarán donde me eduqué yo”” (González, 1905, p. 11).

Hemos presentado, así, las opiniones de cuatro pensadoras medulares de finales del siglo XIX. La preocupación en común es una sola: la educación, porque a través de ella resultarán las futuras mujeres y madres de la nación. Entonces, dicha formación debe seguir con ciertos parámetros. Sin embargo, la misma no era dada a todas las personas por igual, pues el aspecto socioeconómico era, en demasía, vital para estos años. El problema no solo se centraba en el dónde educar, sino en quién educaba, qué contenidos eran recibidos por las educandas y, además, en quiénes podían acceder a esa educación. Lo anterior se hiperbolizaba, puesto que la formación en el hogar no era tomada en cuenta.

\section{Conclusiones}

El tema de la educación fue solo uno de los tantos dentro de una lucha aún más grande. Tal vez incomprensible para las mismas protagonistas de dicho dilema, la dimensión de este iba en aumento al irse develando las injusticias y las carencias por las que tenía que pasar el género femenino.

Toda esta problemática, que va recorriendo décadas y generaciones de intelectuales, se fue polarizando en diversas posiciones fijas y sustentables. Y aunque se tenga la concepción de que con el pasar de los años las cosas se asimilan, mejoran, cambian y se renuevan esto no es tan cierto. Los procesos tienen idas y vueltas, las cuales permiten la reflexión antes de continuar con lo mismo, con algo diferente o con un poco de ambos. Asimismo, un cambio cultural no solo toma tiempo, sino generaciones enteras para ser asimilado. Con ello, no se está haciendo una relación etaria de las autoras, sino generacional.

El período de transición literaria de finales del siglo XIX hasta inicios del siglo XX revisado en este estudio nos deja todavía puntos por resolver, el 
¿qué cambió y cómo?, ¿con qué herramientas discursivas las intelectuales de la época enunciaron sus opiniones?, ¿cómo influyó la obra de cada una de ellas en el desarrollo del papel de la mujer?, etc.

Todas estas interrogantes no deben olvidar el objetivo inicial de este artículo: analizar el rol de la intelectual de esta época "bisagra", específicamente, en su rol de mujer enunciante y en cómo, desde esta posición, construye las imágenes del sujeto mujer (difundidas, principalmente, por medio de la prensa escrita).

\section{Notas}

1. Este término, tal como se conoce actualmente, no era parte del discurso de la época, solo se le ha hecho mención para precisar lo que se pretende demostrar en este artículo.

2. Bas bleu refiere a una mujer de letras o letrada en un sentido peyorativo (pseudoliterata). Por otro lado, el término bleu alude, en uno de sus significados, a la persona que está principiando en sus labores.

3. En todas las citas que se consignan a continuación se han respetado las tildes, grafías y signos de puntuación empleados por cada autora.

4. Este texto fue producto de la visita que Cabello hiciera al Liceo Fanning, colegio dirigido por Elvira García y García. Cabello fue invitada por García para ser espectadora de los exámenes que se les tomaban a las alumnas en el mencionado centro de estudios.

5. Teresa González de Fanning recibió una carta en la cual un grupo de personalidades de la época le solicitaba su permiso para publicar sus artículos bajo el rubro de Educación femenina. Estas mismas serían las que apoyaron a Cabello de Carbonera (César Goycochea, Víctor Larco Herrera, Rafael Larco Herrera, Federico Vásquez, Casimiro Medina, entre otros).

\section{Referencias bibliográficas}

Alvarado Rivera, M. J. (1912). El feminismo: Conferencia leida en la Sociedad Geográfica de Lima el 28 de octubre de 1911. Lima: Imprenta de la Escuela de Ingenieros Julio Mesinas.

Cabello de Carbonera, M. (2017). Los exámenes. En el colegio de la Señorita Elvira García y García. En I. Pinto, Mercedes Cabello de Carbonera. Artículos periodísticos y ensayos (pp. 347-351). Lima: Fondo Editorial del Congreso del Perú.

Cáceres Moreno, Z. A. (1909). Mujeres de ayer y de hoy. París: Garnier Hermanos, Libreros-Editores. 
De la Riva-Agüero y Osma, J. (2008). Carácter de la literatura del Perú independiente. Lima: Instituto Riva-Agüero, Universidad Ricardo Palma.

García y García, E. (1908). Educación femenina. Correspondiente a la misión social que debe llenar la mujer en América. Lima: Imprenta nacional de Federico Barrionuevo.

García y García, E. (1925). La mujer peruana a través de los siglos. Lima: Imprenta Americana.

González de Fanning, T. (1905). Educación femenina, colección de artículos pedagógicos, morales y sociológicos. Lima: Tipografía de "El Lucero".

Larriva de Llona, L. (1898, enero 18). Réplica ineludible. En El Comercio.

Matto de Turner, C. (2006). Aves sin nido. Edición crítica de D. Sales Salvador. Castelló de la Plana: Universitat Jaume I, Ellago ediciones. 